\title{
El patrimonio común entre España y América (de Túpac Amaru a Santa Rosa). Recuerdos personales desde lo material a lo inmaterial ${ }^{1}$
}

\author{
Fermín del Pino Díaz \\ Centro Superior de Investigaciones Científicas (España)
}

Tras alguna explicación inicial que considero necesaria, me propongo mostrar de modo experiencial que en el caso de Hispano-América ${ }^{2}$ se produce un fenómeno relativamente particular, y es que una parte de su patrimonio cultural es compartido con España y, por tanto, es difícil distinguir en cada caso lo que pertenece a uno y a otro.

Tal vez no se trate de un fenómeno nuevo o único, en cuanto que casi todos los pueblos comparten algo con los demás, o por coincidencia de origen $\mathrm{y}$ vecindad o por contacto histórico posterior; $\mathrm{y}$, sin embargo, la variedad no ha desaparecido. De otro lado, el fenómeno típico del mestizaje se puede trasladar metafóricamente del campo biológico al cultural (de lo material a lo inmaterial), sin darse tampoco la total fusión de todos sus elementos en este campo cultural. Como se sabe, al igual que las leyes de la herencia hoy descubiertas (a partir,

\footnotetext{
1 Este modesto ensayo tiene ya algunos años guardado en mi ropero. Por un lado se nutre de mis primeras lecturas en el campo antropológico de los años 60, que fueron motivo luego de un seminario dictado en el Museo Nacional de Antropología sobre Antropología aplicada (curso 67-68), y por otro fue objeto de una conferencia en La Antigua (Guatemala), en abril de 2005, dentro de un Seminario Internacional sobre Patrimonio Inmaterial. Más que un análisis específico, aunque contiene alguno de tipo socio-etnográfico, es un artículo en homenaje a la revista Mercurio Peruano por su rol histórico de pensar Perú desde patrones hispanos.

2 Para esta ocasión prefiero esta denominación arcaica a la de Latinoamérica, porque en la antigua España hubo más elementos patrimoniales que el latino (no sólo el árabe, sino asimismo el fenicio o el visigodo, que formaron parte íntima de las tradiciones costeras e interiores de la variada España). Y, desde luego, dentro de Latinoamérica podría diferenciarse culturalmente lo mismo entre las diferentes regiones, e incluso países. Es cierto que este nombre sirvió bien para oponerse unidos los pueblos latinos al pueblo norteamericano, hegemónico desde el siglo XIX, pero cuando se contempla la diversidad interna de los latinos en EE.UU., que en este momento es una minoría considerable (la segunda del mundo) pero tan variada que se llega a dudar que sea una denominación común pertinente, incluso hablando solo del área vecina (chicanos, cubanos, dominicanos, puertorriqueños y centroamericanos). Si bien es verdad que alrededor del Mediterráneo se fundó una cierta república común de las letras, no sé si podría decirse lo mismo para las tradiciones populares.
}

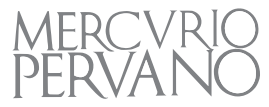


claro, de Mendel y Darwin) no permiten afirmar la herencia total de los rasgos paternos y maternos, cada pueblo que se mezcla elige los componentes que quiere asimilar del exterior. ${ }^{3}$ A veces, a pesar de estos inevitables mestizajes culturales -parciales y selectivos-, también se produce un simple fenómeno contrario de auto-afirmación simbólica, consistiendo muchas veces la oposición patrimonial hispano-americana en una vivencia identitaria, con un componente meramente imaginario.

Tratar de este tema con rigor requeriría de muchas consideraciones previas, no solamente por lo que hace a cada elemento patrimonial, de que se trate -físico o cultural- sino porque había que recurrir a un complicado 'estado de la cuestión' en cada caso. Por eso he decidido reducir mis referencias a dos casos peruanos de fiestas populares que he podido testimoniar personalmente, en los cuales el componente hispano e indiano me ha parecido demasiado evidente: $\mathrm{y}$, sin embargo, esa bilateralidad patrimonial constatada resulta ser equívoca $\mathrm{y}$, también, contestada.

\section{El sentido posesivo de todo patrimonio}

Todo planteamiento patrimonial acerca de cualquier materia tiene el riesgo de atizar respecto a la misma el sentimiento de propiedad -personal o colectivapor parte de los sujetos en relación, y la competencia entre ellos. Es decir, que puede provocar en sus beneficiarios la sensación de alarma permanente, haciéndoles sentir o temer que sus derechos pueden ser no respetados o, incluso, que los demás tienen la intención de tomarlos para sí en cualquier momento. Esta situación naturalmente puede producir peores consecuencias de las perseguidas: tal vez justamente las contrarias. Y ello -aunque se aplique a un tema relativamente poco objetivo y estrictamente no material, como son las culturas- puede ir en contra de lo que se pretende: justamente el respeto o reconocimiento intercultural. A fuerza de defender los derechos de uno, o desde el punto de vista de uno, se termina atentando contra los otros. Ya decía el viejo aforismo romano, summum ius, summa injuria: o sea -aplicado al caso presente, aunque forzadamente- que el rigorismo formalista y conservador respecto a uno de los actores de la escena social -un sujeto individual, una comunidad aldeana, regional o nacional- puede terminar atentando contra el otro y, a la

\footnotetext{
3 Decimos que la herencia biológica es 'selectiva' (no porque se 'elijan' voluntariamente) sino porque no todos los hijos heredan los mismos caracteres, y porque algunos rasgos particulares de la herencia (altura, color de la piel y de los ojos, etc.), se presentan en forma estadística distinta, necesitando algunos de ellos que sean semejantes el padre y la madre para heredarlos (son recesivos, no dominantes). Desde finales del s. XVII hubo consciencia popular en Hispanoamérica de que las mezclas raciales entre blanco, indio y negro se atenían a cierto patrón, que se quiso recoger en cuadros de castas, y se le dieron nombres precisos a cada caso. El propio Garcilaso recoge esta tradición de distinguir con nombre distinto los diversos tipos de mestizos (cuarterones, etc.).
}

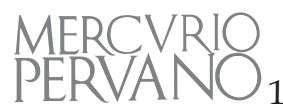


larga, poniendo incluso en peligro el disfrute del derecho patrimonial por parte de su propietario primero.

De hecho, la definición primera que uno encuentra de patrimonio en los diccionarios usuales castellanos -como el de Julio Casares, por ejemplo- es la de "bienes o hacienda que una persona ha heredado de sus ascendientes". No importa si el término tiene luego adjetivos (eclesiástico, real, nacional, local, popular, material, etc.), puesto que esa distinción posterior se refiere solamente a diferentes titulares del mismo o a alguna circunstancia que lo hace variar de contexto, pero no altera el contenido: el de una propiedad detentada desde antiguo por alguien frente a terceros, que la legislación ampara. En la Gran Enciclopedia Larousse francesa (traducida y completada para los países hispánicos por Editorial Planeta, en los años 60), se vuelve a repetir la definición anterior. El patrimonio es, ante todo, un "bien que una persona adquiere hereditariamente de sus ascendientes"; luego se añaden algunos caracteres más (desde el punto de vista biológico, jurídico, histórico y sociológico), entre los cuales se señala como repetido el hecho de que suele ser "inalienable e inembargable". Es decir que ni uno mismo puede desposeerse a sí mismo del derecho a la propiedad misma como parte interesada del sistema patrimonial, en el régimen jurídico que le protege.

Como se ve, toda protección de un derecho patrimonial conlleva la amenaza, proporcional, respecto a quienes pudieran atentar contra el disfrute del mismo: toda protección tiene un castigo como correlato, en caso de incumplimiento. Esto significa que el elemento jurídico que se le añade al objeto de propiedad patrimonial, por sí mismo, necesita estar protegido por parte de un órgano de poder coactivo, para llevarse eficazmente a cabo. Efectivamente, los derechos de propiedad dan lugar en la vida diaria a infinidad de pleitos, incluso al interior de la familia o comunidad que pretende amparar y conservar unida, justamente a través de esos mismos lazos de los que hacen derivar una propiedad patrimonial compartida. Dos hermanos o parientes muy queridos pueden entrar en litigio, cuando creen que su derecho propio se halla en peligro, por causa de la justa competencia como sujetos susceptibles del mismo derecho patrimonial. A veces, y justamente también por vía de compensación, esta disputa patrimonial inesperada conduce luego a revalorizar elementos del propio pasado que no habíamos reclamado para nosotros, hasta que la disputa por ellos con familiares y vecinos nos hizo caer en la cuenta de su valor.

Lo mismo ocurre entre comunidades mayores, incluso internacionales, como sucede en Hispanoamérica con algunos de los litigios fronterizos planteados -por ejemplo- entre Ecuador y Perú, entre Chile y Bolivia, o entre Colombia y Venezuela. Por supuesto, existen también en Eurasia, el llamado Viejo Mundo: por ejemplo, entre Grecia y Turquía, respecto a regiones enteras de la antigua Grecia clásica: hasta el nombre sagrado de Macedonia de una región (que también fue turca y ahora es una moderna República desgajada de la antigua Yugoslavia) es disputado por Grecia, que cree tener mayor derecho 
a usar el viejo y prestigioso nombre, en exclusividad. Esto sería un típico patrimonio inmaterial, el del nombre de un territorio.

Es irónico el hecho de que Grecia se vanagloriase nacionalmente durante siglos frente al imperio otomano solamente de su herencia ortodoxa (de la vieja Constantinopla, capital de Bizancio, convertida ahora en la Sublime Puerta de Estambul), sin recordar sus glorias culturales del pasado clásico. Esto ocurrió así por siglos, hasta que el énfasis de los románticos europeos (alemanes y franceses) le hizo caer en la cuenta a la Grecia de fines del XIX, del gran patrimonio que constituía esa herencia histórica puramente cultural (inmaterial, pero inmarcesible y prodigiosamente rica). Será la época que concluye justamente en los Juegos Olímpicos de 1896 -convocados por Pierre de Coubertin en el París de 1893-, que no hace mucho (entre el 13 y el 29 de agosto de 2004), volvieron a celebrarse como segunda convocatoria griega en Atenas (no fueron reconocidos por el Comité Internacional los juegos intercalados de 1906, entre Saint Louis de 1904 y Londres 1908). Desde entonces, la disputa con el vecino mundo otomano de Turquía no será por el cetro del cristianismo ortodoxo -que hace tiempo pasó a Moscú, llamada desde entonces la tercera Roma, y objeto de sonadas novelas de sus escritores más paradigmáticos, del propio Fedor Dostoievski ${ }^{4}$ - sino por el símbolo patrimonial derivado del siglo de Pericles en el territorio de la Grecia clásica: la mayor parte del cual quedaría posteriormente del lado turco.

Esa famosa novela rusa determinó otras producciones literarias posteriores, también importantes, en otras tradiciones nacionales como Del sentimiento trágico de la vida (1912), o La agonía del cristianismo (1924), por Miguel de Unamuno. O, incluso, como la novela peruana Todas las sangres (1964), del escritor-antropólogo José María Arguedas (cosa que apenas he visto señalar en la bibliografía de referencia). En las dos primeras, Unamuno se planteaba el nuevo destino de España ante la modernidad europea, y la parte que corresponde a las tradiciones religiosas; y en la tercera, Arguedas se debate también entre la tradición y modernidad peruanas, y emplea el mismo hilo conductor de su inspirador ruso, haciendo intervenir en esa disputa de interés histórico nacional a diversos hermanos, uno de ellos ('Demetrio' -Dimitri- Rendón Willca) propuesto como ejemplo por el autor de una solución mestiza, entre la modernidad ajena y la tradición indígena. Así como no fue de todos entendida su intención de estudiar en esta novela la tradición y la modernidad nacional peruana, tampoco se ha entendido por todos la comparación que ensayó poco antes entre España y Perú, en su tesis doctoral (1962-68), referida igualmente a la tradición y modernidad como un eje conductor común en ambos países (entre Puquio y el Mantaro, como entre Bermillo y la Muga). Se trataba de mostrar la capacidad adaptativa de una

\footnotetext{
${ }^{4}$ Los hermanos Karamázov (de 1880) es, tal vez, una de las novelas más conocidas de su autor, y en ella se incluyen episodios como el del gran inquisidor, donde se hace eco su autor de un logro histórico por parte hispana, cuando la dureza inquisitorial empleada por los Reyes Católicos permitió librar al país del cáncer de la desunión religiosa.
}

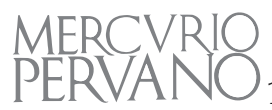


sociedad tradicional (dos de España y dos de Perú) ante los cambios modernos. No le interesaba tanto el mestizaje hispano del Perú -como se ha creído por muchos- como su comparable solución tradicional ante la modernidad externa.

La Grecia nacionalista tomó partido finalmente enfatizando su lado 'laico' dentro del propio pasado histórico, que le distinguía especialmente de su vecina Turquía; ${ }^{5}$ y Rusia también -pero a la contra- volvió a optar recientemente por su identidad religiosa cristiana -heredera directa de la Grecia ortodoxa- eligiendo aquella parte de su patrimonio cultural inmaterial que creía le permitía ofrecer una imagen contrastante y prestigiosa con su competidor Occidente. Fue interesada la ayuda que los zares rusos ofrecieron a Grecia para ayudar a Europa a liberarla del imperio otomano, a comienzos del s. XIX: nada del romanticismo europeo por restablecer el mundo clásico de Pericles. ${ }^{6}$ Grecia se presentaba finalmente como el paladín del viejo Occidente cristiano, y Rusia -su heredero ortodoxo- como su enemigo cristiano principal. Sin embargo, era asimismo simple heredera de un conflicto ajeno: la tercera Roma (Moscú) heredaba el conflicto de Bizancio (la otra Roma) con la Roma original, cuna de Occidente y de la actual Unión Europea. ${ }^{7}$

Algunos antiguos países islámicos como Turquía y Egipto han querido presentarse ante el mundo como naciones con otros rasgos aceptables por la modernidad: el primero suprimiendo formalmente la apariencia religiosa, y el segundo combinando su islamismo con su pasado faraónico, tan admirado igualmente por Occidente. En ambos casos hubo una renuncia al espíritu religioso, ligado a sentimientos imperiales y monárquicos, substituidos por dos líderes militares laicos tan conocidos como Mustafá Kemal Atatürk y Abdel Nasser, ambos presidentes vitalicios de su patria. Conocido es el liderazgo occidentalizante de Atatürk, que lidera el nacimiento de la nación turca en 1923 (hasta su muerte en 1938), renunciando por decreto constitucional a todo rasgo islámico (alfabeto, vestido, calendario, código civil...). Egipto sufrirá el mismo destino anti-religioso y anti-monárquico por parte de un líder, que preside en

\footnotetext{
${ }_{5}$ Sin que ello haya hecho desaparecer el factor religioso y eclesial. En el caso de Grecia, la Iglesia ha conservado el enorme poder inmobiliario que le reconoció el imperio otomano, y posee todavía propiedades que envidia el estado griego. De hecho, el propio primer ministro A. Txipras ha tenido que aceptar la oferta eclesial de asumir la deuda internacional griega, aunque es el primero que juró su cargo ante el presidente laico, no ante los poderosos popes. Ver al respecto el blog hispano "Europa laica".

${ }^{6}$ Fani-María TsigaKou, Redescubrimiento de Grecia. Viajeros y pintores del romanticismo. Barcelona, Ediciones del Serbal, 1985.

7 Sobre los cambios simbólicos ocurridos en el mundo ruso con relación a Europa, y su largo paralelismo con España, organizamos en Madrid hace algunos años (2001) un coloquio entre el C.S.I.C. y el Instituto Pushkin de San Petersburgo, publicado finalmente por Pedro Bádenas y por mí mismo, como Frontera y Comunicación Cultural entre España y Rusia. Una perspectiva interdisciplinar (III Coloquio hispano-ruso), Madrid, Iberoamericana, 2006. En este coloquio se incluyó asimismo mi ensayo “Unamuno, lector de Dostoievski”, pp. 255-268.
} 
1954 la nueva república hasta su muerte en 1970. Pero, en lugar de renunciar a su cultura árabe, propondrá presidirla a nivel internacional (llegando a unir su país a Irak por unos años) y a liderar el movimiento de países no alineados. Desde entonces, ambos países Turquía y Egipto han mantenido una actitud de aproximación a Occidente, que no ha logrado eliminar del todo las tendencias islámicas de su numerosa población.

Otro tanto de lo metafórico que hay en los casos griego y ruso, mutatis mutandis, cabe decir delámbito egipcio moderno, que no toma conciencia nacional de su herencia cultural faraónica hasta que la presencia napoleónica -y la consiguiente competencia suscitada entre arqueólogos europeos: especialmente de ingleses, alemanes y franceses- le induce a descubrir una parte substancial de su patrimonio cultural, opacada anteriormente por la omnipresencia otomana. En estos momentos se trata del país islámico más cercano a Occidente, donde primeramente se estudiaron también los elementos islámicos a una nueva luz de la modernidad europea (por ejemplo, con la inauguración de periódicos y partidos políticos en clave árabe). ${ }^{8}$

Como se ve, esta posibilidad de competición patrimonial no se reduce solamente al patrimonio material, aunque la maledicencia social atribuye la mayor parte de los pleitos de herencia a los intereses creados, y finalmente al dinero y los beneficios derivados de pingües herencias. Cantidad de narraciones históricas de viejos conflictos sociales, e incluso de conocidas novelas de intriga (de Sherlock Holmes, o de Poirot) se basan sobre parientes que no esperaban el resultado desfavorable de un testamento, y que hacen lo imposible por asegurar su propio beneficio. Con frecuencia, también, una gran parte de las peleas aldeanas nacen en una herencia familiar, físicamente conflictiva. Pero otras veces, las disputas tienen como causa la competencia por puros valores inmateriales, a veces por simples sentimientos de amistad $u$ hostilidad: antiguos amigos pueden llegar a ser enemigos encarnizados. A veces, lo que conduce a la disputa es una situación de simple envenenamiento de tradicionales buenas relaciones entre antiguos familiares, por cuestiones de precedencia o autoestima. $\mathrm{Y}$ esto vale tanto para individuos como para grupos sociales y nacionales.

\section{El patrimonio cultural común entre España e Hispanoamérica}

Quienes hemos visitado América desde España hemos sentido profundamente la misma impresión de familiaridad cultural que sienten los latinoamericanos cuando pasan a España desde otro país europeo (incluso

\footnotetext{
${ }^{8}$ Un repaso crítico a este proceso dialéctico de identidad nacional en Egipto, entre Oriente y Occidente, lo ofrece $\mathrm{M}^{\mathrm{a}}$ Luisa OrTEGA, "Visión de los otros y visión de sí mismos entre Oriente y Occidente. El caso de Egipto", en F. Del Pino y C. LÁzAro (Coordinadores) Visión de los otros y visión de sí mismos. ¿Descubrimiento o invención entre el Nuevo Mundo y el Viejo? Madrid, CSIC, Biblioteca de Historia de América, nº 12, 1995, pp. 235-250.
}

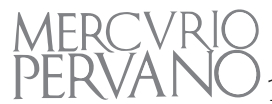


latino como Francia). Sobre todo, esa sensación existe si esta visita recíproca sucede luego de viajar a otros países diferentes. En mi caso, la visita a un país americano de habla española (a Perú, fundamentalmente, a partir de 1971) se produjo tras estancias más o menos breves en algunos países vecinos del mío: Francia, Italia, Portugal y Marruecos. No solamente nos son familiares en el otro país hermano las experiencias sensoriales (los sonidos, los sabores) sino sobre todo las relaciones interpersonales: no es solamente que hablemos la misma lengua, comamos los mismos menús o casi a las mismas horas, o que nos vistamos de la misma manera, etc. Es que interpretamos mejor fuera de casa los gestos mudos: las miradas, incluso los ruidos, porque nos resultan familiares. ${ }^{9}$ A pesar de ello, esta familiaridad no borra del todo la sensación natural de novedad: los españoles hablamos más alto y rápido que los latinoamericanos, usamos más el aceite de oliva o la carne de cerdo, y nos gusta definir más nítidamente los términos de una relación interpersonal. Los latinoamericanos son más circunspectos y educados, no dicen nunca no a secas, y en España necesitan distinguir a su llegada que no estamos enfadados con alguien, aunque le gritemos a nuestro interlocutor.

Naturalmente hay diferencias recíprocas también dentro de España, como dentro de Hispanoamérica, y existen también los mismos pleitos de vecinos que en Europa, y tal vez los mismos matices que distinguen a uno de otro. Desde luego, aunque lleva tiempo a un extraño distinguir entre miembros de países vecinos -entre un cubano y un venezolano, entre un argentino y un uruguayo, o entre dos países centroamericanos- es evidente que ellos mismos aprecian muy bien sus diferencias: como un andaluz distingue a un extremeño, un castellano viejo a otro manchego o un catalán a un valenciano. Pero, no obstante, lo mismo que un catalán aprecia mayor diferencia con un andaluz que con un valenciano (aunque probablemente se lleve mejor con el andaluz), los hispanos aprecian también la mayor diferencia con un latino que con otro peninsular, aunque en ambos casos de trate de parientes reconocibles.

Ahora bien, como digo, a pesar de esta relación evidente de familia entre hispanos e hispanoamericanos -que todavía es reconocible por ambos lados-, es un hecho que ha habido entre ellos algunos pleitos a lo largo de la historia, como no podía ser menos entre países emparentados. No me refiero solamente a la conocida interrupción formal de la vida política común, a partir de los diferentes movimientos de independencia a comienzos o fines del s. XIX, sino a los malentendidos comunes durante los largos períodos de convivencia colonial, o luego en la convivencia internacional ocurrida tras la independencia. Me voy a referir particularmente a estos, y en especial a dos

\footnotetext{
${ }_{9}^{9}$ MalinowsKi (1922) declaraba que una señal de habernos adaptado los antropólogos al pueblo bajo estudio, es cuando distinguimos entre los ruidos normales y los que no, sin necesidad de ver lo que ocurre. Ver su introducción a Los argonautas del Pacífico occidental. Barcelona, Península, 1972.
} 
casos de fiestas populares, o desfiles municipales, en los cuales se rememora simbólicamente algún momento traumático de la conquista o de la represión política. Es decir, quiero recordar dos casos recientes a los cuales he podido asistir en situación de espectador cercano -como turista y como antropólogo-, donde se ha reclamado simbólicamente una posición americana de enfrentamiento cruento con las tropas españolas (de una comunidad local, pero con valor de imagen política nacional y étnica) como patrimonio cultural distintivo.

\section{Primer caso del Perú. La celebración de las fiestas patrias}

Las describo brevemente para que se obtenga una idea más precisa del fenómeno que propongo analizar: en los años 1971-75, llevé a cabo tres campañas de trabajo de campo en la región selvática de Madre de Dios, en el Perú sud-oriental fronterizo con Brasil y Bolivia, junto con varios alumnos y colegas españoles: ${ }^{10}$ estaba entonces al frente del gobierno de la nación un consorcio militar dirigido por el general Juan Velasco Alvarado, que dedicaba una especial atención nacional a esta zona fronteriza, donde la presencia de fuerzas militares quedaba por ello reforzada. Esto no hacía más que aumentar la tendencia a un comportamiento particularmente nacionalista, que se daba en todo el país, sobre todo en los primeros años. Por abreviar la descripción de la situación a que me refiero, diré que se producían frecuentes manifestaciones públicas, auspiciadas por el nuevo gobierno militar hacia la herencia cultural española pasada, tanto en la celebración del día de Fiestas Patrias (el 28 de julio, fecha que me tomó tres veces sobre el terreno) como en algunas manifestaciones solemnes más periódicas.

A la hora de los partes diarios radiados, se solía recordar enfáticamente la muerte del cacique indígena José Gabriel Condorcanqui, que murió despedazado en 1780 por orden de las autoridades españolas, por rebelarse violentamente al frente de una considerable multitud de indios y mestizos, protestando contra la subida de impuestos y otros abusos de las autoridades españolas del Perú: el líder indigenista del siglo XVIII se proclamaba heredero de Túpac Amaru,

\footnotetext{
${ }^{10}$ Mi interés particular se centró en el sector migrante de la sierra vecina (Cusco y Puno), que ocupaba la mano de obra principal de los servicios públicos de Puerto Maldonado, los empleados de bancos y -por supuesto- los campesinos dispersos por los campamentos suburbiales de la capital, especialmente del Tambopata. Sector migrante que ocupaba entonces el mismo rol demográfico y económico que la importante migración japonesa de comienzos de siglo, de quienes se pensaba entre colegas antropólogos que tenían serios problemas de adaptación ecológica y política. Apenas he publicado mis resultados en este campo. Véase “Trabajos de antropología en Puerto Maldonado (Perú)". Revista española de Antropología americana, vol. VII: 2, 1972, págs. 424-32. Madrid; y “Migración y adaptación: el caso de los serranos en el Departamento selvático de Madre de Dios (Perú)". Atti del XL Congresso internazionale degli Americanisti, III: 499-510. Roma, 1974. Recogido con modificaciones en Alberto ChIRIF (Ed.): Etnicidad y ecología, Lima: Ediciones del Centro de Investigación y Promoción Amazónica, 1979, pp. 53-83.
}

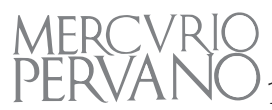


el joven inca que ajusticiara el virrey Toledo en la plaza del Cusco en 1572, tras detenerlo en las selvas peruanas en rebeldía contra las fuerzas españolas que habían ido a proponerle un pacto colonial, aceptado por él finalmente. Este doble gesto rebelde durante la colonia, en los siglos XVI y XVIII, contrastaba con el comportamiento normalmente colaboracionista de la élite incaica, mantenida así al frente de las comunidades aldeanas por las autoridades españolas -sobre todo el sur del Perú-, y reelegida periódicamente como herederos del inca vencido, Atahualpa.

El libro de cabecera del segundo cacique rebelde, Túpac Amaru II, había sido la obra cumbre de la literatura peruana, Los comentarios reales de los incas, debida a la pluma del mestizo -incluso de nombre- Garcilaso de la Vega, el Inca. En ella se recordaba con minuciosa precisión -y excelente literatura castellanael patrimonio cultural incaico de los tiempos antiguos, debido a su madre, con el mismo orgullo que el cristianismo nuevamente introducido, simbolizado por la figura solemne de su padre. Ambas partes formaban lo que se conoce como primera y segunda parte, de la obra, aunque la preferida por su sucesor Túpac Amaru II era la primera, obviamente: donde basaba sus reclamaciones patrimoniales, materiales e inmateriales. Este efecto retardado de un libro sobre una rebelión masiva popular provocó la discreta recogida del libro por parte las autoridades españolas. ${ }^{11}$

De hecho, el libro había sido bien acogido originalmente por sus amistades cordobesas, que se sentían mencionadas en los prólogos y compartían con él la erudición clásica de que hacía gala: gran parte de sus amigos y maestros eran conversos andaluces, ${ }^{12}$ que consideraron conveniente como recurso

11 Creo que fue el arqueólogo John H. Rowe el primero que analizó detenidamente la complejidad del uso dado a la versión garcilasiana de 1723 en la rebelión de Condorcanqui, en la que se aludía a una supuesta amenaza inglesa (Walter Raleigh) de rebelión contra las autoridades españolas, en apoyo de los incas vencidos. Cf. "El movimiento nacional inca del siglo XVIII", Revista Universitaria, Cusco, 155: 17-47, 1955. De hecho, su artículo ha sido reproducido y citado mucho como la obra de referencia. Mario Cárdenas encontró un documento que prueba que Condorcanqui poseía un ejemplar de Garcilaso, en "José Gabriel Tupa Amaro, a propósito de un documento", Histórica, IV (2), pp. 229-232. Sobre el tema ver el ensayo de José Durand, "El influjo de Garcilaso en Túpac Amaru", Copé, II (5), 1971, pp. 2-7.

${ }^{12}$ Se suele saber que en Andalucía se conservaba más que en otra parte de España huella del pasado árabe, pero no tanto que también había un fuerte componente judaico, que formaba parte de la convivencia medieval de las tres culturas del libro (cristianismo, islamismo y hebraísmo). Sobre esta composición constituyó su teoría histórica de España el conocido historiador de la literatura hispánica Américo Castro (La realidad histórica de España, México, 1954), y todavía Córdoba se ufana de ser la sede de las tres culturas (antes que México lo reivindicase como nombre para su plaza de Tlatelolco). En esta Andalucía es donde vino a vivir y escribir su historia el Inca Garcilaso, y trabó amistad especial con la comunidad jesuita andaluza, donde hasta 1593 se permitió el acceso de descendientes conversos de familias moriscas y judías, especialmente de éstas. Gracias a ello, un historiador jesuita andaluz propuso que había encontrado acogida especial el mestizo Blas Valera, en sus últimos años de 
histórico referirse a las antigüedades romanas para exaltar el prestigio andaluz, más bien que referirse al otro lado de su rico patrimonio cultural propio, la herencia islámica árabe (de la que la Andalucía actual echa mano abundante en su reivindicación de identidad frente al gobierno castellano de Madrid). El propio Garcilaso de la Vega el inca está enterrado desde su muerte en 1617 en la mezquita de Córdoba, convertida en catedral: pues terminó formando parte de esta tertulia de canónigos, pero nunca se le ocurrió reclamar esta parte islámica de su patrimonio cultural, como descendiente de andaluces. Él siempre se refirió en su obra más bien al precedente cultural romano, por lo que hace a su herencia cristiana materna, puesto que lo consideraba un buen testimonio -aunque metafórico- del papel civilizador incaico en las tierras salvajes de los Andes, preparando como Roma el triunfo final del cristianismo.

Pero el gobierno militar peruano actual se refería en sus alocuciones radiofónicas de los años 70 al Inca Garcilaso incaísta, más bien como lectura de cabecera del líder Túpac Amaru II prohibida por el gobierno español en Perú: y, por tanto, a una versión unilateral y truncada de su patrimonio cultural, el materno. En realidad, aunque no tan exagerada, ésta es todavía la tendencia interpretativa que ha dominado en la sociedad peruana, desde siempre. Si bien los historiadores modernos y los antropólogos encuentran hoy la obra del Inca Garcilaso demasiado aculturada y romanizada (transformando a favor de esta versión retocada los testimonios frecuentes de politeísmo y sacrificios humanos, recogidos como habituales en otras fuentes tempranas), sin embargo esta obra es verdaderamente popular en el país: la figura del mismo preside las escuelas más alejadas del agro andino, y la imaginación de todo peruano de pro, al que se dedican premios literarios y estadios deportivos.

Por el contrario, la figura de otro autor no menor, la del cronista Huamán Poma de Ayala (indio por ambos lados de su herencia y autor de una larga reclamación escrita al rey Felipe III en pro de un buen gobierno en los Andes, tolerante con ambas partes de la república) es solamente reclamada por el estamento culto del país, y por los antropólogos, siendo apenas conocido entre los estamentos populares. ${ }^{13}$

Volviendo al caso de la referencia radiofónica, primera por las autoridades peruanas, la de Túpac Amaru II en los años 70, importa destacar el hecho de que esta radio de Puerto Maldonado estaba gestionada entonces, justamente

vida: Francisco de Borja Medina, "Blas Valera y la dialéctica 'exclusión-integración del otro'". Archivum Historicum Societatis Iesu, 68 (1999), 229-268.

${ }^{13}$ Se contaba entre mis colegas limeños una anécdota reciente sobre un periodista -que dirigía la entrega de un premio con el nombre de Huamán Poma de Ayala en un concurso popular en los Andes- al cual se le cruzaron los chicotes (los cables) a la hora de llamar al estrado al afortunado beneficiario del premio: se le ocurrió llamar a recibirlo al propio Huamán Poma en persona, confundiendo los papeles. Eso habría sido impensable si el premio se hubiera llevado el nombre del Inca Garcilaso.

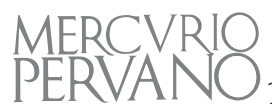


por la orden dominica: todos ellos españoles. ${ }^{14}$ Pero esas autoridades extranjeras desfilaban en primer lugar el día de Fiestas Patrias, como representantes legítimos de una fuerza social local, y en su teatro escolar se escenificada con frecuencia otro mito indígena aprovechado por el gobierno militar para encender el fervor nacional, conocido como Incarri (pronunciación quechua de Inca rey): en virtud del cual se esperaba que la cabeza del inca Túpac Amaru cortada por las autoridades españolas (la de ambos, el de 1572 y el 1780), enterrada aparte de su cuerpo ya descuartizado (para que no pudiera nunca ser reconocido, reconstruido), crecería en su tumba hasta reconstruir un día el cuerpo completo. ${ }^{15}$ Este mito de Incarri alimentaba en tiempos coloniales -y continua haciéndolo hasta nuestros días, según descubrió Arguedas en colaboración con su discípulo Alejandro Ortiz- las esperanzas del pueblo llano, que siempre confió en el poder armonizador y vivificador de la figura del Inca. Hoy día lo llaman los historiadores peruanos utopía incaica (Flores Galindo, Manuel Burga), pero los antropólogos preferimos hablar de mito popular, de esperanza mítica y mesiánica (Juan Ossio).

Ahora bien, el hecho tiene también su lado paradójico, que conviene atender. La paradoja a que quiero referirme es al hecho mismo de que la sociedad actual (la peruana) recurra reiteradamente a incidentes traumáticos del pasado -que dividen la sociedad real en dos, e incluso repudian la participación simbólica de una fuerza realmente presente, los españoles- para obtener un mejor resultado simbólico de su patrimonio cultural inmaterial. A este respecto, me acuerdo de otra anécdota que me ocurrió visitando monumentos incaicos cercanos de Cuzco, donde un guía jovencito nos explicaba a los turistas -entre los cuales nos hallábamos varios españoles- que la antigua riqueza incaica procedente de esos monumentos (que alimentaba el poderío del imperio antiguo incaico sobre toda la sierra peruana) había sido robado por los españoles, y había permitido su dominio imperial por el resto del mundo. Hasta que los ingleses se lo robaron a los españoles y -a su vez- luego lo hicieron los ejércitos norteamericanos: todos los cuales fundaron y mantuvieron cada uno su propio imperio, a base del mismo oro. Independientemente de la coincidencia mayor o menor con la

\footnotetext{
14 Acabo de enterarme por Google que existe un nuevo obispo dominico español en Puerto Maldonado, Monseñor David Martínez, que está preparando para dentro de unos días la visita papal a Puerto Maldonado, el 19 de enero de 2018. Su predecesor Mons. Francisco González (2008-2014), asimismo español, se enfrentó a los poderes fácticos internacionales que querían hacer pasar la carretera inter-oceánica por el centro de Puerto Maldonado, y logró ser apoyado popularmente por laicos y por la misma conferencia episcopal peruana.

${ }^{15}$ Lo más probable es que esta esperanza popular de resurrección del Inca -el Incarri- sea la elaboración popular -o aceptación desesperada por parte de la masa indiana- de la promesa de los misioneros, el día de la ejecución del primer Túpac Amaru de que resucitaría el día del Juicio Final y se salvaría eternamente. Es discutido si la idea del alma inmortal y la resurrección corporal sea o no parte del patrimonio andino, y entre sus reclamadores a favor se hallaba el Inca Garcilaso.
} 
realidad -que a muchos no nos parece sorprendente- lo más interesante es cómo el relato 'estandarizado' del rico patrimonio peruano recurría al expolio incaico por las tropas españolas para enfatizar el valor perenne de este rapto 'imperial', de tanta trascendencia para la historia mundial.

Causa sorpresa la frecuente presencia de estos abusos y saqueos del pasado en el imaginario nacional presente. Un peruano ilustre (Ricardo Oré, antiguo y entrañable ministro que fue de la embajada peruana en España) me señalaba con alguna frecuencia -cuando escuchábamos juntos canciones peruanas patrióticas, en ocasiones centenarias- que la mayor parte de los personajes y hechos que salen en el himno peruano son vencidos y derrotas, no victorias propias: lo cual le producía extrañeza. Quizá no sea tan extraño y excepcional este procedimiento de señalar con énfasis los agravios recibidos pasados como base de la identidad política presente. Ante todo, por el conocido precedente de acumulación de agravios para crecer el valor de la reclamación patrimonial ante el resto de la humanidad. Toda injuria ajena pasada es susceptible de ser empleada en el haber nacional, y de hecho (de acuerdo a la conocida teoría de F. Barth sobre el focus fronterizo de las imágenes nacionales) ${ }^{16}$ es un procedimiento muy común para desarrollar conciencia de identidad nacional. Efectivamente, el primer componente de toda reclamación nacionalista es el victimismo, demostrar que se es víctima de algún abuso ajeno injustificado.

Creo que a esta razón se debe que fuera posible -incluso solicitado en mi caso, y en el de otros componentes españoles- asistir a estas ceremonias oficiales peruanas, a pesar de pertenecer a una comunidad nacional que era objeto de esa precisa reclamación patrimonial, a nivel simbólico. Evidentemente se hacía diferencia entre las personas reales y los personajes simbolizados en la ceremonia, lo que permitía el desdoblamiento de mis dos facetas de persona real, y de miembro de una comunidad nacional. Pero también creo que operaba mi presencia personal -simbólicamente- como receptora de ese mensaje de protesta nacionalista, en cuanto que era considerado de alguna manera como un miembro heredero de esa parte del Perú que había oprimido a la otra, a la indígena, de la cual se consideraban descendientes el conjunto de la comunidad nacional.

En el caso peruano, al contrario que en México, no todos se consideran herederos de esa porción nacional conocida en tiempos coloniales como 'la república de los indios'. Algunos peruanos -y no ciertamente incultos ni atrasados ni carentes de sentimientos distinguidos, como el muy conocido escritor Vargas Llosa- sienten una inconsciente distancia respecto de aquel sector de la población a quien se llama 'indio', y consideran que el progreso nacional consiste en 'integrarlos' a todos en la vida moderna. Gran parte de las disidencias que hubo de Vargas Llosa con el otro escritor peruano de altura,

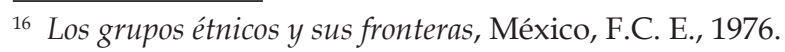

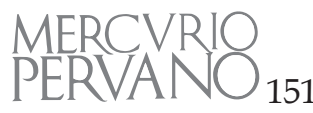


Arguedas, tienen que ver no tanto con estilos literarios, aunque reales, como con ese diferente imaginario hacia el componente 'indio'. En una sociedad así dividida en dos como la peruana (donde el racismo opera a la luz del día, aunque solapado), el visitante español queda siempre en una posición particular, ciertamente incómoda, cuando se le supone formar parte de la república de españoles'. Si un español quiere participar en ese tipo de sociedad, y quiere ejercer como antropólogo, ciertamente tiene que permanecer muy alerta para no caer víctima de cualquiera de los bandos, pues ambos le reclaman como parte interesada: uno en nombre de su genealogía hispana y otro en nombre de su profesión.

Cuando asiste a una representación festiva peruana, en que los españoles del pasado ocupaban el papel del bando opresor (ajusticiando al inca Túpac Amaru, o prohibiendo la lectura del Inca Garcilaso), el español testigo puede sentir en su propia piel el peso que ese pasado 'caricaturizado' tiene para los actores actuales, que no consideran del todo superada la pasada matriz colonial. A veces, lo que llama la atención es precisamente la importancia que se atribuye hoy todavía al período colonial, y lo determinantes que parecen haber sido en la memoria colectiva peruana los actos de unos cuantos actores del pasado, ciertamente trágicos; pero excepcionales en su estatuto de indiano rico, por relación al conjunto masivo de actores hispanos que ligaron su vida a estas tierras, eligiéndolas como su nueva patria, y desplegaron una actividad cotidiana de clara integración social, que no se tiene en cuenta para nada en la memoria nacional.

\section{Una fiesta patronal. Santa Rosa de Lima en Carhuamayo}

Lo que me pasó en Madre de Dios en los 70, volvió a pasarme hace pocos años, cuando fui a participar en unas jornadas nacionales dedicadas al escritor/ antropólogo Arguedas (2011), y este desplazamiento me permitió dedicar un fin de semana a contemplar una fiesta popular en el interior del país, el día de Santa Rosa de Lima (la semana del 23 al 30 de agosto). No necesito mencionar la importancia de la fiesta de Santa Rosa en Perú, su patrona y la primera santa americana, materia tan conocida en la academia peruana: lo que nos importaba de esta fiesta local era que se hacía a la vez -en el mismo escenario casi- que una fiesta andina, dedicada al inca Atahualpa. Así fue como visité por tres días la comunidad alto-andina de Carhuamayo (Junín), cerca de las minas de La Oroya, a unos 4,200 ms. de altura sobre el mar, en compañía de tres colegas peruanos interesados en la fiesta (uno de ellos, nacido en una comunidad vecina, había realizado además trabajo de campo en la comunidad). ${ }^{17}$

\footnotetext{
17 Aunque éste no es un ensayo etnográfico, no puedo menos de citar dos estudios de Luis Millones, referidos a Carhumayo, y su peculiar mezcla con la fiesta de Atahualpa: El Inca por la colla. Historia de un drama popular en Los Andes peruanos, Fundación Fredrich Ebert, Lima, 1988;
} 
No insistiré en las duras condiciones de vida que se tienen a esa altura, tan diferente a las vividas en la experiencia anterior, en plena selva tropical. Si en Madre de Dios, las altas temperaturas, la vegetación exuberante y la presencia de mosquitos contaminaban por sí solos un modo de vida, aquí eran lo mismo, pero por todo lo contrario: las condiciones de vida difíciles en una puna tan elevada dejaban poco espacio para vegetales y animales, al contrario que en la siempre verde floresta tropical. Uno de los acompañantes pasó una tarde entera reponiéndose del llamado mal de altura o soroche. La primera noche, pasada en un hostal popular, fue terrible además por las bajas temperaturas.

Afortunadamente el pueblo estaba en fiestas, las comparsas de música se alternaban por las calles, en la plaza se construían andamios para tablados improvisados, y todo el mundo circulaba con nerviosismo y excitación por las calles. Los puestos ambulantes ofrecían todo tipo de productos al paseante, y no paraban de pasar gente engalanada al compás de una orquesta pequeña de música, rodeados de danzantes uniformes vestidos lujosamente. Todo esto ocurría desde la misma hora de nuestra llegada, un sábado ya anochecido, y tuvimos que hacer un enorme esfuerzo personal para incorporarnos al ambiente festivo, saliendo de nuestro terrible malestar (con mareo y dolor de cabeza), nuestra incomodidad física general y otras sorpresas físicas.

En la primera noche, consultando el libro de fiestas que se repartía por doquier, por manos generosas (cada cofradía editaba una versión diversa, con publicidad propia), supimos aproximadamente que el programa de fiestas duraba una semana, y que podríamos contemplar en la mañana del lunes la misa solemne de Santa Rosa, así como el sacrificio de la llama por parte de unos actores distinguidos, vestidos de Atahualpa y su corte. Eso es lo que nos había atraído al lugar, lo que llamábamos mestizaje ritual entre la fiesta de Santa Rosa y de Atahualpa. Efectivamente, tras la misa solemne cantada por un obispo peruano venido ex profeso, las dos andas de Santa Rosa y el Niño Jesús se paseaban por la plaza principal del pueblo, siendo escoltadas por las sucesivas orquestas reunidas, y las numerosas comparsas, que se sucedían en ordenada sustitución. Al término de la misma, y subido en sus andas también, el inca Atahualpa -autorizado por la Santa, y ya sin la compañía del obispo- era llevado por sus servidores y un ejército bien engalanado al estadio municipal, para el sacrificio de la llama.

Nosotros estuvimos durante tres días en estos sucesivos actos, como observadores atentos y a veces como actores principales, invitados por los mayordomos de la fiesta a participar en ella. Y ése es el punto que quiero enfatizar sobre todo, porque nos permite comprender mejor la organización social que llevaba a cabo la fiesta, y al mismo tiempo, la mezcla de mensajes

\footnotetext{
"La otra historia: Rosa de Lima en las voces de Quives y Carhuamayo", Revista Canadiense de Estudios Hispánicos, Vol. 23, No. 3, (Primavera 1999), pp. 475-481.
}

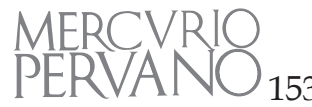


y argumentos históricos que se manejaban en la misma. Más que una fiesta pública, con autoridades financiadoras, el verdadero patrón de la misma eran algunas familias que habían sido elegidas como mayordomos ese año: exactamente cuatro mayordomos, que eran quienes desfilaban solemnemente por las calles, rodeados de sus comparsas y orquestas propias: a estos cuatro, representados por el matrimonio y sus parientes, se le sumaban doce apus o señores importantes que también desfilaban o coordinaban los elementos diversos de la fiesta. Llevaban escritos sus cargos de apu en el vistoso sombrero, y en bandas al pecho engalanadas a propósito, y se supone -dado el sistema cuatrienal incaica- que cada mayordomo era servido por cuatro ayudantes.

Ellos eran los que desfilaban orgullosos en la calle, en la plaza mayor y en el estadio, acompañados por numerosos comparsas de actores (vestidos de incas o de cargos con oficios coloniales: demonios, payasos, servidores negros). Ellos ofrecían todo el tiempo bebidas y comidas en sus casas, o en salones preparados para la ocasión, y se supone que estaban conformados por empresarios exitosos de la localidad, o venidos de fuera, pero nacidos en Carhuamayo. La región que le rodea es relativamente rica, sobre todo, por el comercio a nivel nacional que despliega desde tiempos coloniales, alimentando el trasiego de una región minera, y actualmente comunicando las explotaciones selváticas con la superpoblada capital de la República. La flota de camiones inundaba las calles y plazas, y sus choferes se ven por todas las carreteras nacionales.

Esta generosidad de los mayordomos es evidente en cualquier sitio que se visite del pueblo, siendo uno asaltado por hombres vestidos de fiesta (con sombrero de fieltro y traje uniformemente de oscuro) para tomarse un café con pastas, o lo que pida, urgido a ello reiteradamente. El venir nosotros de Lima y de España era muy tenido en cuenta, y pregonado a los asistentes, incluso relatado minuciosamente por los altavoces en el estadio. En la concentración en el estadio final, cuando la gran ceremonia del sacrificio de la llama por el inca y sus capitanes, me invitaron a sentarme en la fila primera de los asientos reservados a las autoridades, que saludaban a cada una de las comparsas, y autorizaban los pasos de la fiesta. Entonces, los locutores de radio anunciaron mi presencia, junto con la de los otros colegas peruanos que me acompañaban, lo mismo que anunciaban cada una de las partes de la ceremonia, en forma de glosadores oportunos.

Lo que me llamó más la atención, al contrario que a mis acompañantes limeños, fue esta jugosa y cordial comensalidad civil de los mayordomos y apus, no los desfiles callejeros o en el estadio, ni el aparato ritual que les acompañaba. Era el énfasis en hacernos consumir alimentos y bebidas abundantes en sus casas, abiertas de par en par, y adornadas incluso en el frontispicio de sus ventanas por las cabezas de las reses sacrificadas, y en los patios de sus casas por todos los animales dispuestos al consumo: era ese espíritu evidente de potlatch -de convite dispendioso- lo que me tenía prendado y me atraía de la celebración de la fiesta de Santa Rosa en Carhuamayo. Insistían siempre, a porfía, en que 
volviéramos a la siguiente comida (participamos en una cena y un desayuno, en casa de apus diferentes), y a un baile en la municipalidad, donde un personaje de la municipalidad acogía a otro de los mayordomos. Las redes clientelares usaban todos los medios a su alcance, para realce del convite. Tuvimos que bailar con ellos, cada vez que nos vieron, y beber a porfía de unos y de otros, llegando al extremo la resistencia de nuestros pobres cuerpos, cansados e inadaptados a esa altura y temperatura.

En un afán tal vez desmedido por hallar referentes etnográficos de prestigio para el propio caso de estudio, y ante la sorpresa de mis colegas peruanos, trataba de recordar mis lecturas profesionales del caso (de Franz Boas, Bronisław Malinowski y Marcel Mauss). Creo que no nos hemos dedicado suficientemente a aplicar a las fiestas hispanoamericanas estas categorías reconocidas de la etnografía mundial, y es seguro que el estudio del compadrazgo y la estructura clientelar de nuestras fiestas hispanas y americanas se iluminarían en gran parte, aplicándole el esquema o modelo del potlatch norteamericano. Desde luego, aunque es evidente el peso de la tradición andina en una comunidad instalada a 4,200 metros, no exagero si declaro que la mayor parte de sus componentes me resultaban familiares, y de hecho me podía desenvolver con facilidad inesperada en aquel intercambio de gestos y conductas, entre anfitrión e invitados, donde mi procedencia española no sólo no provocaba extrañeza sino, al contrario, era buscada especialmente, y hasta pregonada.

\section{A modo de conclusión}

Pero, por no alargar el relato personal, me interesa concluir poniendo la mirada, no sólo sobre estos evidentes paralelismos entre fiestas españolas y americanas, sino en el uso de la conquista española como traca final de la fiesta cristiana. En ella el inca Atahualpa, tras el desfile ordenado de cada una de las comparsas y orquestas de los doce patronos de la fiesta ante el estrado del estadio, dedicaban el sacrificio de una llama -que siempre fue cruenta, pero que en los últimos años el movimiento ecologista ha logrado que no pase de simbólica-, a concluir el día de la fiesta de Santa Rosa. Luego de ello, en días siguientes, se celebraría el ritual de la victoria cristiana sobre Atahualpa, naturalmente sintiéndose los habitantes identificados con el bando vencido, como ocurre en muchas fiestas de moros y cristianos en España (recuérdese todo el aparato de estas comparsas moriscas en la zona oriental hispana, y la deleitación popular con sus músicas, orquesta, vestidos multicolores y tracas ruidosas, signos todos del mundo islámico en España). Por cierto, que una de las piezas musicales normalmente usada en estos casos (el pasodoble llamado Paquito chocolatero) forma parte integrante de cualquier programa de baile popular o familiar, en el que todos los participantes se unen a la danza. Es posible que en las sociedades americanas, la popularidad de estas danzas rituales no hayan permeado tanto al conjunto moderna de la misma sociedad, aunque hay canciones andinas

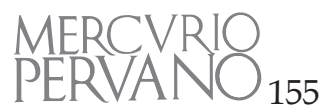


muy celebradas en la nueva sociedad urbana, y en general es común cerrar las celebraciones (bodas, bautizos) con huaino y marinera. ${ }^{18}$

Los españoles que han presenciado versiones americanas de estas fiestas de conquista, y han podido verificar la satisfacción festiva y ritual que les produce nuestra presencia actual dentro de ellas, tal vez podemos interpretar el sentido y la vivencia de la fiesta popular de un modo, si no más verdadero, al menos de un modo complementario al que recibe de sus testigos americanos. Creo indudable que la convivencia actual entre ambos tipos de intérpretes -hispanos y americanos- puede ser tan fácil y natural debido al estrecho emparentamiento histórico que han desplegado desde hace cinco siglos nuestros pueblos.

${ }_{18}$ Agradezco a Carlos Arrizabalaga este detalle musical peruano. 